\title{
Association of Hypoxic Ischemic Encephalopathy with Hyponatremia in Term Infants within first 24 hours of Life
}

\author{
ITAAT ULLAH KHAN AFRIDI ${ }^{1}$, HUMA AFRIDI ${ }^{2}$, BEENISH RIAZ ${ }^{3}$, SEHRISH IFTIKHAR ${ }^{4}$ \\ ${ }^{1}$ Prof of Paediatrics, Nawaz Sharif Medical College, Gujrat \\ ${ }^{2}$ Asst Prof Obs \& Gynae, Nawaz Sharif Medical College, Gujrat \\ ${ }^{3}$ Asst Prof Obs \& Gynae, Islamic International Medical College, Rawalpindi \\ Correspondence to Prof Itaat Ullah Khan Afridi, Email itaatafridi@yahoo.com, cell: 00923214253314
}

\begin{abstract}
Background: Electrolytes disturbances observed in hypoxic ischemic encephalopathy can further complicate the already asphyxiated babies Serum sodium is one of the most important electrolytes associated with neuronal activity, routinely serum sodium is added after 24 hour of life in maintenance fluid of neonates but we will monitor the changes in our suspected cases earlier so that early intervention should be done to reduce the perinatal mortality and its fatal outcomes.

Aim: To determine the association of hyponatremia with hypoxic ischemic encephalopathy in term infants during first 24 hours of life.

Methods: Case control study was carried out at Department of Pediatrics, Aziz Bhatti Shaheed Teaching Hospital Gujrat from $12^{\text {th }}$ Feb 2018 to $12^{\text {th }}$ Feb 2019. 134 cases and 134 controls were included in the study. Full term babies (>37 weeks) of either gender was included for both cases and controls. Cases were hypoxic ischemic encephalopathy infants who has history of delayed cry at birth of $>5$ minutes, respiratory distress and moaning. Hyponatremia was labelled if serum sodium levels are below $130 \mathrm{mmol} /$ lit. Matched controls i.e. healthy neonates from same setting were selected for the study. The serum sodium levels were compared between cases and controls.

Results: Serum sodium was unequally distributed among cases \& controls (Median $\pm \mid Q R$ 136 $\pm 5,139 \pm 8, P$ value using Mann Whitney $U$ test= 0.01$)$. Hyponatremia was also unequally distributed among cases \& controls $(3.4 \%$ vs $0.4 \%$, P value using Fischer exact test $=0.01$ ). Logistic regression analysis using STEP wise analysis proved that the association found regarding hyponatremia/ serum sodium with hypoxic ischemic encephalopathy is not significant after adjusting for weight and gender of the infant. The distribution of birth weight and gender among cases and controls was similar ( $P$ value $>0.05$ ).

Conclusion: It is concluded that hyponatremia is not associated with hypoxic ischemic encephalopathy in term infants during first 24 hours of life.

Keywords: Hypoxic ischemic encephalopathy, Hyponatremia, Serum sodium, Perinatal asphyxia
\end{abstract}

\section{INTRODUCTION}

Despite of much advances in perinatal care, birth asphyxia is still a global problem. Its incidence is 2-9 per 1000 live full term births worldwide ${ }^{1}$ while in developing counties it accounts for one hundred to two hundred and fifty per one thousand births ${ }^{2}$. In addition to its incidence, it causes major proportions of neonatal deaths e.g. $23 \%$, after infections $35 \%$ and prematurity $28 \%$. Thus it became third leading cause of neonatal deaths globally,4.

Perinatal asphyxia has multi systemic effects but central nervous system insult in form of hypoxic ischemic encephalopathy is the most concerned as it is permanent and has long term neurological sequelae ${ }^{5}$. Hypoxic ischemic encephalopathy has variable outcomes depending upon the degree of severity. According to WHO, though the chances of neonatal mortality has been decreased from 5 million during 1990 to 2.4 million till 2019, still neonates face the great hazard of mortality during neonatal period of 28 days. During 2019, 47\% of all children deaths that occurred in under five years of age, occurred in neonatal period with around $1 / 3^{\text {rd }}$ deaths occurred on the day of delivery or the day of birth and near to three quarters deaths within first week of life ${ }^{6}$. Every

Received on 14-03-2021

Accepted on 17-07-2021 year, perinatal asphyxia causes approximately four million neonatal deaths all over the world. But, the overall incidence and prevalence of birth asphyxia is not known still for Eastern and Central African countries ${ }^{7}$.

The diagnosis of perinatal asphyxia can be done by suing the Apgar score of neonate which could be $<7$ after 5 minutes of birth. Value of Apgar score than ranges between four to seven indicates the moderate birth asphyxia while the value of Apgar score that ranges from zero and three indicates severe birth asphyxia. ${ }^{8}$ Severe form of birth asphyxia may lead to severe multi-organ failure that may cause brain damage, respiratory failure due to dysfunction of lungs, cardiomyopathy, renal dysfunction, hepatic failure and necrotizing enterocolitis ${ }^{9}$.

Serum electrolytes have vital importance to many physiological processes in body as any disturbance in their normal values leads to serious outcome. So, body keeps their concentration in specific limits to ensure the adequate homeostasis ${ }^{10,11}$. Metabolic and electrolytes disturbances are also observed in hypoxic ischemic encephalopathy $1,12,13,14$. Serum sodium is one of the most important electrolytes associated with neuronal activity. In a study by Rehman $\mathrm{F}$ et al, the researchers found that hyponatremia is present in $30 \%$ of the asphyxiated babies while only $15 \%$ in total population ( $p$ value $<0.001$ ) and 
these disturbances further complicate the already asphyxiated babies ${ }^{15}$.

Knowledge of hyponatremia and its timely management is very crucial in improving the outcome of Hypoxic ischemic encephalopathy as birth asphyxia is a preventable problem but its long term neurological sequelae are almost untreatable and render the children handicapped for whole life. There are studies that shows the correlation of birth asphyxia and serum sodium but this study aims to detect these changes earlier e.g. within 24 hours of life. Routinely serum sodium is added after 24 hour of life in maintenance fluid of neonates but we will monitor the changes in our suspected cases earlier so that early intervention should be done to reduce the perinatal mortality and its fatal outcomes

\section{MATERIALS \& METHODS}

After approval of study for local ethics committee, this Case control study was conducted in the Department of Pediatrics in collaboration with Department of Obstetrics \& Gynecology, Aziz Bhatti Shaheed Teaching Hospital Gujrat from $1^{\text {st }}$ July 2019 to $30^{\text {th }}$ April 2021. Calculated sample size was 268 (134 cases and 134 controls) by taking prevalence of hyponatremia as $30.1 \%$ patients and $15 \%$ in control, ${ }^{15}$ at $95 \%$ confidence interval and $80 \%$ power of study. For both cases and controls full term babies ( $>37$ weeks) of either gender were included only as determined by hospital antenatal records. Cases were those who had hypoxic ischemic encephalopathy i.e. history of delayed cry at birth of $>5$ minutes, respiratory distress (when neonate experiences difficulty in taking breaths manifested as rapid or irregular breathing pattern) and moaning (low sustained mournful cry usually indicative of pain or sorrow). Controls were healthy neonates admitted for observation only were included in the study. Neonates who were premature $(<37$ weeks) and IUGR, Neonates with congenital anomalies, Infants of mothers with hypertension and diabetes were not included in the study. Non-probability consecutive sampling was used to include the patients in the study. Informed consent from parents was taken. Detailed history and examination of each patient done under the supervision of senior registrar and their samples for serum sodium levels were sent to the hospital laboratory within 24 hours. Reports were assessed and if serum sodium level found to be $<130 \mathrm{mEq} / \mathrm{L}$, then hyponatremia was labeled. Patients with hyponatremia were managed according to hospital protocols. Data was entered into the attached proforma. Data analyses was done using SPSS version 23.

\section{RESULTS}

In this study, out of 134 cases, there were $82(61.2 \%)$ males and $52(38.8 \%)$ females. Out of 134 controls, there were $85(63.4 \%)$ males and 59(36.6\%) females (Table 1$)$.

Test of normality (Shapiro-Wilk test) was applied on birth weight of neonate and serum sodium level. It has been observed that the value of Shapiro-Wilk test was significant for birth weight of neonate showing that the variable birth weight was not following normal distribution ( $p$-value $<0.05$ ). Similarly, it was observed that the value of Shapiro-Wilk test was significant for serum sodium level of neonate showing that the variable serum sodium level of neonate was not following normal distribution ( $p$-value < 0.05) (Table 2).

As birth weight was not following normal distribution, so it was presented as median with interquartile range. Among cases, the median birth weight was $2800(300)$ while median birth weight of control group was 2700(300). The difference in both groups regarding median birth weight was insignificant $(P$ value $>0.05$ ). Similarly, serum sodium level was not following normal distribution, so it was presented as median with interquartile range. Among cases, the median serum sodium level was 136(5) while median serum sodium level of control group was 139(8). The difference in both groups regarding median birth weight was significant $(P$-value $<0.05)$ and cases had significantly lower serum sodium level than controls (Table 3).

Out of 268 neonates, there were $10(4 \%)$ neonates who had hyponatremia, while $258(96 \%)$ had normal serum sodium level (Fig 1).

Among cases, there were $9(6.7 \%)$ neonates had hyponatremia while $125(93.3 \%)$ had normal serum sodium level. Among controls, there were $1(0.75 \%)$ neonates had hyponatremia while $133(99.25 \%)$ had normal serum sodium level. The difference was significant ( $p$-value $<0.05)$, showing a significant difference in both groups for hyponatremia (low serum sodium level). Odds ratio was calculated as $9.576(95 \%$ confidence interval $=1.196,76.67)$, showing that there was about tem times more chances of developing hyponatremia in neonates with hypoxic ischemic encephalopathy in term infants during first 24 hours of life (Table 4).

Table 1: Distribution of gender in both groups

\begin{tabular}{|l|c|c|c|c|}
\hline \multirow{2}{*}{ Gender } & \multicolumn{2}{|c|}{ Case } & \multicolumn{2}{c|}{ Control } \\
\cline { 2 - 5 } & $\mathbf{n}$ & $\%$ & $\mathbf{n}$ & $\%$ \\
\hline Male & 82 & $61.2 \%$ & 85 & $63.4 \%$ \\
\hline Female & 52 & $38.8 \%$ & 49 & $36.6 \%$ \\
\hline
\end{tabular}

Table 2: Tests of normality for distribution of birth weight and sodium level

\begin{tabular}{|l|c|c|c|}
\hline \multirow{2}{*}{} & \multicolumn{3}{|c|}{ Shapiro-Wilk } \\
\cline { 2 - 4 } & Statistic & df & Sig. \\
\hline Birth weight in grams & 0.888 & 268 & $<0.001$ \\
\hline Serum sodium in mmol/Lit & 0.310 & 268 & $<0.001$ \\
\hline
\end{tabular}

Table 3: Comparison of birth weight and serum sodium level in both groups

\begin{tabular}{|c|c|c|c|c|c|c|c|c|}
\hline & \multicolumn{4}{|c|}{ Cases $(n=134)$} & \multicolumn{4}{|c|}{ Controls $(n=134)$} \\
\hline & Mean & Median & SD & IQR & Mean & Median & SD & IQR \\
\hline Birth Weight (grams) & 2862 & 2800 & 290 & 300 & 2823 & 2700 & 260 & 300 \\
\hline \multicolumn{9}{|c|}{$P$ value Mann Whitney $U$ test $=0.29$} \\
\hline Serum Sodium (mmol/Lit) & 138 & 136 & 16 & 5 & 138 & 139 & 4 & 8 \\
\hline
\end{tabular}


Fig 1: Distribution of hyponatremia in neonates

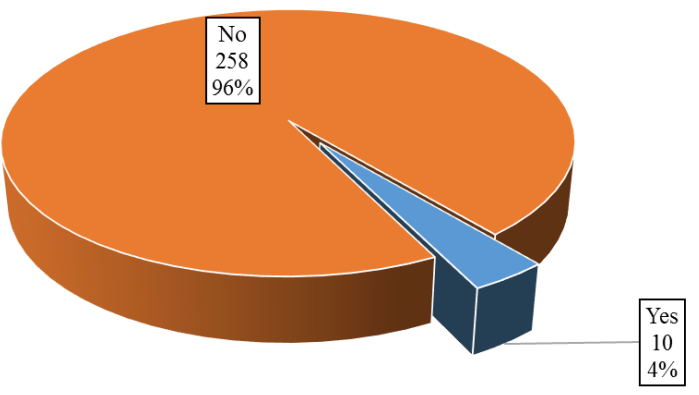

Table 4: Distribution of Hyponatremia among cases \& controls

\begin{tabular}{|l|c|c|c|c|}
\hline \multirow{2}{*}{ Hyponatremia } & \multicolumn{2}{|c|}{ Case } & \multicolumn{2}{c|}{ Control } \\
\cline { 2 - 5 } & $\mathrm{n}$ & $\%$ & $\mathrm{n}$ & $\%$ \\
\hline Yes & 9 & $6.7 \%$ & 1 & $0.75 \%$ \\
\hline No & 125 & $93.3 \%$ & 133 & $99.25 \%$ \\
\hline Odds ratio & \multicolumn{4}{|c|}{$9.576(95 \%$ confidence interval $=1.196,76.67)$} \\
\hline
\end{tabular}

$P$ value 0.0099

\section{DISCUSSION}

Neonatal encephalopathy is the diverse condition in which neonates show symptoms of central nervous system malfunction. Any child with an aberrant degree of awareness, fits, tone and reflex disorders, suffocation, aspiration, feeding problems or an abnormal hearing screen should be evaluated for neonatal encephalopathy ${ }^{16-18}$.

The frequency of newborn encephalopathy varies depending on how it is defined, although published estimates range from 2 to 9 per 1000 term infants. As the phrase "neonatal encephalopathy" grew more popular, it was discovered that between 1991 and 2000, the diagnosis of "birth asphyxia" decreased in one United States community. In a 2010 analysis, the incidence of newborn encephalopathy was estimated to be 3.0 per 1000 live births $(95 \% \mathrm{Cl} 2.7-3.3)$, whereas the incidence of hypoxic ischemic encephalopathy (a subgroup of neonatal encephalopathy) was estimated to be 1.5 per 1000 live births (95 percent $\mathrm{Cl}$ 1.3-1.7) ${ }^{19}$

Metabolic and electrolytes disturbances are also observed in hypoxic ischemic encephalopathy. Serum sodium is one of the most important electrolytes associated with neuronal activity. ${ }^{19}$ Some investigators require stringent criteria for using the term neonatal encephalopathy, such as two or more symptoms of encephalopathy lasting over 24 hours, while others require no more than a low five minute Apgar score. ${ }^{20}$ However, the use of Apgar scores alone is problematic, as Apgar scores may be low due to maternal analgesia or prematurity, or can be normal in the presence of acute hypoxia-ischemic injury ${ }^{21,22}$.

A sodium level of less than $135 \mathrm{mEq} / \mathrm{L}$ in the plasma or serum is used to diagnose hyponatremia. When plasma or serum electrolytes are acquired during an assessment for another ailment, the diagnosis is frequently discovered by chance, especially in children with values between 130 and $135 \mathrm{mEq} / \mathrm{L}$, but levels below $130 \mathrm{mEq} / \mathrm{L}$ are more frequently linked with clinical signs and symptoms. ${ }^{23,24}$
Serum sodium was unequally distributed among cases \& controls (Median \pm IQR $136 \pm 5,139 \pm 8$, P value using Mann Whitney $U$ test $=0.01)$. Hyponatremia was also unequally distributed among cases \& controls (3.4\% vs $0.4 \%, P$ value using Fischer exact test $=0.01)$. Logistic regression analysis using STEP wise analysis proved that the association found regarding hyponatremia / serum sodium with hypoxic ischemic encephalopathy is not significant after adjusting for weight and gender of the infant.

Our results are different from previous studies. In a study by Rehman $\mathrm{F}$ et al, the researchers found that hyponatremia is present in $30 \%$ of the asphyxiated babies while only $15 \%$ in total population ( $p$ value $<0.001)^{15}$. Shamaoon et al., discovered through a cross sectionals study that blood sodium was $137.711 .69 \mathrm{mg} / \mathrm{dl}$ (normal range) and concluded that mean serum electrolyte levels in neonates with perinatal birth asphyxia and mild hypoxic ischemic encephalopathy were within normal range. ${ }^{25}$ Hassan et al., found a negative linear association between sodium levels and the degree of asphyxia in an Iraqi investigation of electrolyte disruption in asphyxiated newborns ${ }^{26}$.

Limitations of current study include single center study with small sample size and also the follow-up.

\section{CONCLUSION}

It is concluded that hyponatremia is significantly associated with hypoxic ischemic encephalopathy in term infants during first 24 hours of life with normal birth weight. Thus in future, it is recommended that neonates delivered at term, must be screened for serum sodium level in order to timely detect hyponatremia and early management must be started in order to prevent occurrence of hypoxic ischemic encephalopathy.

\section{REFERENCES}

1. Masood N. Correlation of serum electrolyte changes with severity of birth asphyxia in newborns. Journal of Rawalpindi Medical College 2016;20(1):27-9.

2. Lawn JE, Blencowe H, Oza S, You D, Lee AC, Waiswa P, et al. Every Newborn: progress, priorities, and potential beyond survival. The Lancet 2014;384(9938):189-205.

3. Campbell OM, Calvert C, Testa A, Strehlow M, Benova L, Keyes E, et al. The scale, scope, coverage, and capability of childbirth care. The Lancet 2016;388(10056):2193-208.

4. Chaturvedi S, Upadhyay S, De Costa A. Competence of birth attendants at providing emergency obstetric care under India's JSY conditional cash transfer program for institutional delivery: an assessment using case vignettes in Madhya Pradesh province. BMC pregnancy and childbirth 2014;14(1):1-11.

5. Denihan NM, Boylan GB, Murray DM. Metabolomic profiling in perinatal asphyxia: a promising new field. BioMed research international 2015;2015.

6. WHO. Newborns: improving survival and well-being. WHO; 2020 [cited 2021]; Available from: https://www.who.int/news$\mathrm{room} /$ fact-sheets/detail/newborns-reducing-mortality.

7. Workineh $\mathrm{Y}$, Semachew A, Ayalew E, Animaw W, Tirfie M, Birhanu M. Prevalence of perinatal asphyxia in East and Central Africa: systematic review and meta-analysis. Heliyon 2020;6(4):e03793-e. 
8. Cunningham F, Leveno K, Bloom S, Spong CY, Dashe J. Williams obstetrics, 24e: Mcgraw-hill New York, NY, USA; 2014.

9. Bayih WA, Yitbarek GY, Aynalem YA, Abate BB, Tesfaw A, Ayalew MY, et al. Prevalence and associated factors of birth asphyxia among live births at Debre Tabor General Hospital, North Central Ethiopia. BMC Pregnancy and Childbirth 2020 2020/10/28;20(1):653.

10. Moore KL, Persaud TVN, Torchia MG. The developing human-e-book: clinically oriented embryology: Elsevier Health Sciences; 2018.

11. Maries E, Hoehn K. Fluids, electrolytes and acid base balance. Human anatomy and physiology, 9th edition Newjersey: pearson education 2012:991-02.

12. Kiyani AN, Arshad Khushdil AE. Perinatal factors leading to birth asphyxia among term newborns in a tertiary care hospital. Iranian journal of pediatrics 2014;24(5):637.

13. Aijaz N, Huda N, Kausar S. Disease burden of NICU, at a tertiary care hospital, Karachi. Journal of the Dow University of Health Sciences (JDUHS) 2012;6(1):32-5.

14. Ashish K, Wrammert J, Clark RB, Ewald U, Vitrakoti R, Chaudhary $\mathrm{P}$, et al. Reducing perinatal mortality in Nepal using helping babies breathe. Pediatrics 2016;137(6).

15. Rahman F, Siddique MAB, Hassan MW, Bari MN, Ahmed F. A study on electrolyte imbalance in asphyxiated neonates. KYAMC Journal 2017;7(2):775-9.

16. Wyckoff MH, Wyllie J, Aziz K, de Almeida MF, Fabres J, Fawke J, et al. Neonatal life support: 2020 international consensus on cardiopulmonary resuscitation and emergency cardiovascular care science with treatment recommendations. Circulation 2020;142(16_suppl_1):S185S221.

17. Soar J, Maconochie I, Wyckoff MH, Olasveengen TM, Singletary EM, Greif R, et al. 2019 international consensus on cardiopulmonary resuscitation and emergency cardiovascular care science with treatment recommendations: summary from the basic life support; advanced life support; pediatric life support; neonatal life support; education, implementation, and teams; and first aid task forces. Circulation 2019;140(24):e826-e80.

18. Ansari AH, Cherian PJ, Caicedo A, Naulaers G, De Vos M, Van Huffel S. Neonatal seizure detection using deep convolutional neural networks. International journal of neural systems 2019;29(04):1850011.

19. Kurinczuk JJ, White-Koning M, Badawi N. Epidemiology of neonatal encephalopathy and hypoxic-ischaemic encephalopathy. Early human development 2010;86(6):32938.

20. Hagberg $\mathrm{H}$, Gressens $\mathrm{P}$, Mallard $\mathrm{C}$. Inflammation during fetal and neonatal life: implications for neurologic and neuropsychiatric disease in children and adults. Annals of neurology 2012;71(4):444-57.

21. Ravelli AC, Eskes M, de Groot CJ, Abu-Hanna A, van der Post JA. Intrapartum epidural analgesia and low Apgar score among singleton infants born at term: A propensity score matched study. Acta obstetricia et gynecologica Scandinavica 2020;99(9):1155-62.

22. Cnattingius $S$, Norman $M$, Granath $F$, Petersson G, Stephansson O, Frisell T. Apgar score components at 5 minutes: risks and prediction of neonatal mortality. Paediatric and perinatal epidemiology 2017;31(4):328-37.

23. Thakur J, Bhatta NK, Singh RR, Poudel P, Lamsal M, Shakya A. Prevalence of electrolyte disturbances in perinatal asphyxia: a prospective study. Italian journal of pediatrics 2018;44(1):1-6.

24. Baranala SK, Kumar N. A study of renal parameters and serum electrolytes level in newborns with birth asphyxia. International Journal of Health and Clinical Research 2020;3(12):306-10.

25. Shamaoon M, Razzaq N, Ahsan M, Ahmad A, Maqbool T, Chaudhary AJ. Electrolyte imbalance in neonates with hypoxic ischemic encephalopathy: A single center study. The Professional Medical Journal 2020;27(10):2159-64.

26. Hasan BA, Al-Ani MH. Electrolyte disturbance in asphyxiated neonates in maternity hospital in Erbil, Iraq. Medical Journal of Babylon 2019;16(4):331. 